\title{
Smoking affects periodontal health
}

Sir,

Smoking is on the rise in the developing world; however, falling in developed nations. About 15 billion cigarettes are sold daily or 10 million every minute. ${ }^{[1]}$ Cigarette smoking is a risk factor for many diseases, and recent evidence indicates that smoking adversely influences 
periodontal health having a detrimental impact on oral health. ${ }^{[2]}$ To reveal this fact a cross-sectional study was carried out in the Shimla city. A total of 371 male subjects were selected by a simple random sampling for the clinical examination. Age group of the study population was between 18 years and 58 years. Each sextant was defined for codes as follows: healthy, scored as Community Periodontal Index (CPI) code 0; bleeding observed on probing, CPI code 1; calculus detected, CPI code 2; pocket of 4-5 mm, CPI code 3; or pocket of $6 \mathrm{~mm}$ or more, CPI code 4 . All the subjects were interviewed regarding the smoking habit. The percentage of healthy periodontium was significantly higher in non-smokers $(3.49 \%)$ than in smokers $(2.81 \%)$. The percentages of CPI scores ' $O$ ' was higher among non-smokers than non-smokers whereas scores $(1,2,3$, and 4) were higher in smokers than in non-smokers. The difference was a statistically highly significant for scores 3 and $4(P<0.01)$. Similar results were seen in the study by Garre et al. ${ }^{[3]}$ and Rosa et al., ${ }^{[4]}$ which has revealed that smoking is positively related to periodontitis. Keeping in view this revealed fact of association between smoking and poor periodontal health, there is a great need of awareness to be created among all sections of society by oral health professionals. People should also be educated about other harmful effects of smoking on general health as well. Dental public-health efforts, therefore, need to include, and emphasize the role of the smoking and not only oral hygiene in the primary preventive efforts.

Vinay Kumar Bhardwaj, Pravesh Jhingta ${ }^{1}$, Deepak Sharma ${ }^{1}$, Shailee Fotedar
Department of Public Health Dentistry, ${ }^{1}$ Periodontology, H. P. Government Dental College and Hospital, Shimla, Himachal Pradesh, India

\section{Address for correspondence: Dr. Vinay Kumar Bhardwaj, Department of Public Health Dentistry H. P. Government Dental College and Hospital, Shimla - 171 001, Himachal Pradesh, India. \\ E-mail:dr.viney@gmail.com}

\section{REFERENCES}

1. Matthews JB, Chen FM, Milward MR, Wright HJ, Carter K, McDonagh A, et al. Effect of nicotine, cotinine and cigarette smoke extract on the neutrophil respiratory burst. J Clin Periodontol 2011;38:208-18.

2. Haber J. Smoking is a major risk factor for periodontitis. Curr Opin Periodontol 1994;27:12-8.

3. Gaare D, Joelimar FA, Ouderaa FV, Rolla G. A cross-sectional study of DMFT and CPITN scores in a group of Indonesian soldiers. Scand J Dent Res 1989;97:20-4.

4. Rosa GM, Lucas GQ, Lucas ON. Cigarette smoking and alveolar bone in young adults: A study using digitized radiographs. J Periodontol 2008;79:232-44.

\begin{tabular}{|l|l|}
\hline \multicolumn{2}{|c|}{ Access this article online } \\
\hline Quick Response Code: & Website: \\
\hline & www.ejgd.org \\
\cline { 2 - 3 } & \\
\hline
\end{tabular}

